\title{
Comparative assessment of umbilical cord blood with peripheral venous blood using hematological scoring system as an early predictive screening method for the detection of early-onset neonatal sepsis in the tertiary care center of Central India
}

\author{
Sunil Arya', Gagandeep Shukla², Prachi Goyal ${ }^{3}$, Urvashi Channa ${ }^{4}$ \\ ${ }^{1}$ Associate Professor, ${ }^{2}$ Postgraduate Resident, ${ }^{3,4}$ Assistant Professor, Department of Pediatrics, M.G.M. Medical \\ College and M.Y. Hospital, Indore, Madhya Pradesh, India
}

Background: Sepsis is one of the major causes of neonatal morbidity and mortality. Early recognition and diagnosis of early-onset neonatal sepsis (EONS) is difficult because of the variable and non-specific clinical presentation of this condition. Hence, there is a need for early predictive screening method for EONS. Aims and Objectives: To compare the umbilical cord blood Haematological Scoring System (HSS) with peripheral venous blood as an early predictive screening method for detection of EONS. Materials and Methods: 100 inborn neonates with two or more risk factors for EONS, chosen by sequential sampling method were included in this prospective analytical study. Blood samples were collected from the umbilical cord and peripheral vein analyzed for hematological parameters, sepsis screen, and peripheral smear for HSS of Rodwell et al., send for blood culture. Blood cultures were performed as gold standard for diagnosing neonatal sepsis and sepsis screen was done to corroborate the diagnosis of neonatal sepsis. Results: Of 100 neonates, 21 belongs to sepsis; 14 to probable sepsis; 65 to no sepsis. HSS in umbilical cord blood (UCB) had Sensitivity-74.28\%, Specificity-92.30\%, PPV-83.87\%, NPV-86.95\% and HSS in PVB had Sensitivity-62.85\%, Specificity- 87.69\%, PPV-75.86\%, NPV-81.69\%. Conclusion: HSS score in UCB can be used as a simple, quick, cost-effective, and readily available screening test with decent sensitivity and high specificity, for the detection of EONS.

Key words: Hematological scoring system; Neonatal sepsis; Umbilical cord blood
Copyright (c) 2022 Asian Journal of Medical Sciences

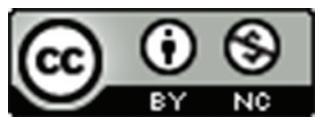

This work is licensed under a Creative Commons Attribution-NonCommercial 4.0 International License.

\section{INTRODUCTION}

Neonatal sepsis is the most common cause of neonatal mortality. Incidence of neonatal sepsis in India is 30/1000 live births (NNPD database). ${ }^{1}$ Early onset neonatal sepsis (EONS) has a subtle and varied clinical presentation in the initial stages. Aggressive approach to diagnosis and management is the principle determinant of the prognosis. Early diagnosis of EONS is the corner stone to reduce the case fatality rate. $^{2}$
EONS usually occurs in the first $72 \mathrm{~h}$ of life, with $80-90 \%$ of cases presenting up to $48 \mathrm{~h}$ after birth. EONS manifests as fulminant, multisystem illness usually acquired by vertical transmission from the mother with high case fatality rate. ${ }^{2}$

The usual practice is to collect blood sample by venipuncture from the neonates and sent for culture and hematology, which can induce pain or infection or iatrogenic anemia to the neonates. There are very few previous documented 
reports of early predictive screening methods for EONS using cord blood sample.

The definitive diagnosis of EONS is made by a positive blood culture, which requires a minimum of 48-72 $\mathrm{h}$, yields a positive result in $30-40 \%$ of cases. Blood culture remains the gold standard for the diagnosis of neonatal sepsis, yet it is important to develop effective screening tools which can presumably diagnose or exclude EONS at the time of presentation.

As no single individual hematological parameter is superior in comparison to another in predicting EONS, a combination of these parameters in the form of hematological scoring system (HSS) has been recommended. For early diagnosis of EONS, the HSS was introduced in the past by Rodwell et al. ${ }^{3}$ It included hematological parameters and showed that such score could accurately predict the presence or absence of infection and be reliable. The HSS has practical advantages - it is applicable to all infants, including those who have received antibiotic therapy prior to evaluation and simplifies the interpretation of hematologic profile. HSS is significant in many other ways, regarding its easy availability, accessibility, low cost, less time consuming, and practically possible in all the laboratories, which makes it convenient for any person to get a high-risk neonate tested and diagnosed on time.

\section{Aim and objectives}

To compare the umbilical cord blood HSS with peripheral venous blood (PVB) as an early predictive screening method for detection of EONS.

\section{MATERIALS AND METHODS}

This prospective analytical study was carried out in nursery of tertiary care center of Central India over a period of 1 year from May 2019 to May 2020 after getting clearance from the Ethics and Scientific Review Committee in which 100 inborn neonates delivered with the presence of 2 or more of the following risk factors (Inclusion Criteria ${ }^{2}$ ) were included in the study by sequential sampling method:

a) Prematurity ( $<37$ weeks)

b) Preterm Premature rupture of membranes

c) More than 3 vaginal examinations after rupture membranes/1 unclean vaginal examination

d) History of maternal fever

e) Foul-smelling liquor

f) Chorioamnionitis

g) Prolonged rupture of membrane $(>18 \mathrm{~h})$

h) Prolonged labour $>24 \mathrm{~h}$

i) Perinatal asphyxia (Apgar score of $<4$ in $1 \mathrm{~min}$ )

j) Meconium stained liquor

k) Neonates born with lethal congenital anomalies and outborns were excluded.
UCB is collected (4-6 $\mathrm{ml})$ at birth under asepsis from the placental end of umbilical artery or vein and send for $\mathrm{CBC}$, peripheral smear for HSS, sepsis screen and blood culture. Similarly PVB sample is also taken within $6 \mathrm{~h}$ of birth for above investigations before starting antibiotics according to NICU protocols.

Demographic, birth and clinical details of all the subjects is recorded and tabulated. After admission baby is assessed for the clinical signs of sepsis and the hematological parameters and culture reports once arrived was recorded and HSS scoring is done.

Diagnostic outcomes of all subjects were divided into three categories:

- Neonates with no signs of sepsis in the next $72 \mathrm{~h}$ with peripheral venous blood culture (PVBC) sterile will be considered normal or no sepsis group

- Neonates with clinical signs of sepsis with sepsis screen \pm with PVBC sterile, were diagnosed as probable/clinical sepsis

- Neonates with clinical signs of sepsis and PVBC showing growth were grouped as proven sepsis. ${ }^{4}$

For the purpose of this study, we used Rodwell's et al., HSS: ${ }^{3}$

\begin{tabular}{llc}
\hline Criteria & Abnormality & Score \\
\hline Total WBC count & $\leq 5000 /$ microliter & 1 \\
& $\geq 25000$ at birth & 1 \\
& $\geq 30000-12-24 \mathrm{~h}$ & 1 \\
& $\geq 21000-$ day 2 onwards & 1 \\
& No Neutrophil & 2 \\
Total neutrophil count & Increased/decreased & 1 \\
& Normal $(1800-5400)$ & 0 \\
Immature neutrophil & Increased (>600/microliter) & 1 \\
count & & \\
Immature: Total & $>0.2$ & 1 \\
neutrophil ratio & & \\
Immature: Mature & $>0.3$ & 1 \\
$\begin{array}{l}\text { PMN Ratio } \\
\begin{array}{l}\text { Degenerative } \\
\text { changes in PMN }\end{array}\end{array}$ & Toxic granules/dohle bodies/ \\
Platelet count & cytoplasmic vacuoles & 1 \\
\hline
\end{tabular}

Interpretation of HSS: $:^{5}$

\begin{tabular}{ll}
\hline Score & Interpretation \\
\hline$<2$ & Sepsis is unlikely (HSS-ve) \\
$>3$ & $\begin{array}{l}\text { Sepsis is probable } \\
\text { (HSS+ve) }\end{array}$ \\
\hline HSS: Haematological scoring system &
\end{tabular}

\section{Statistical analysis}

Statistical analysis was carried out for all 100 inborn high-risk neonates for EONS. The data were expressed in terms of rates, ratio, and percentages. Chi-square test was used to compare or associate nominal data. A probability 
value ( $\mathrm{P}$ value) of less than 0.05 was considered statistically significant. Using the above data statistical parameters - sensitivity, specificity, positive predictive value (PPV), negative predictive value (NPV) of UCB and PVB, HSS is calculated and compared.

\section{RESULTS}

Baseline characteristics of subjects were studied. Mean gestational age was 34 weeks and mean birth weight was $2.2 \mathrm{~kg}$ (Table 1). The risk factors found statistically significant with sepsis $(\mathrm{P}<0.05)$ are maternal fever followed by prematurity, prolong rupture of membrane, preterm premature of rupture of membrane, chorioamnionitis, foul-smelling liquor (Table 1).

Of 35 sepsis cases which presented with clinical features of EONS (Table 2), the commonest clinical manifestation was respiratory distress $(69 \%)$.

Distribution of diagnostic outcome of all 100 high risk neonates for sepsis (Figure 1).

So out of 100 neonates, HSS score in UCB was +ve in 31 neonates in which 26 belong to sepsis (proven+probable sepsis) and 5 belong to no sepsis group. HSS score was -ve in 69 neonates in which nine belong to sepsis and 60 belong to no sepsis group (Table 3). Similarly in PVB, HSS score was positive in 29 neonates in which 22 belong to sepsis and 7 belong to no sepsis group. HSS score was negative in 71 neonates in which 13 belong to sepsis and 58 belong to no sepsis group (Table 3).

Statistical parameters values of HSS in UCB to detect EONS is higher than in PVB (Table 4).

\section{DISCUSSION}

For a definite diagnosis of sepsis peripheral blood culture results are gold standard which is time-consuming. The other recent available markers are sensitive but expensive.

\begin{tabular}{lcc} 
Table 2: Distribution of clinical features of EONS \\
\hline Clinical features & \multicolumn{2}{c}{$\begin{array}{c}\text { Sepsis } \\
\text { (Proven+Probable) } \\
\text { (n=35) }\end{array}$} \\
\cline { 2 - 3 } & No. & $\%$ \\
\hline Respiratory distress (tachypnoea, & 24 & 68.57 \\
grunting, chest retraction) & & \\
Shock & 20 & 57 \\
Lethargy & 16 & 45.7 \\
Abdominal distension & 13 & 37 \\
Feeding difficulty/intolerance & 11 & 31 \\
Bleeding/altered orogastric aspirate & 11 & 31 \\
Seizure & 10 & 28.6 \\
Hypoglycemia & 8 & 22.8 \\
Jaundice & 7 & 20 \\
Fever & 5 & 14 \\
Others & 14 & 40 \\
\hline EONS: Early-onset neonatal sepsis & \multicolumn{2}{l}{}
\end{tabular}

\begin{tabular}{|c|c|c|c|c|c|}
\hline Patient's Profile & $\begin{array}{l}\text { No Sepsis } \\
(n=65) \\
\text { No. }(\%)\end{array}$ & $\begin{array}{c}\text { Probable Sepsis } \\
(n=14) \\
\text { No. }(\%)\end{array}$ & $\begin{array}{c}\text { Proven Sepsis } \\
(n=21) \\
\text { No. }(\%)\end{array}$ & $\begin{array}{c}\text { Total } \\
\text { No. (\%) }\end{array}$ & $P$ value \\
\hline \multicolumn{6}{|l|}{ Gender } \\
\hline Male & $30(46.1)$ & $5(35.7)$ & $6(28.6)$ & $41(41.0)$ & \\
\hline Female & $35(53.8)$ & $9(64.3)$ & $15(71.4)$ & $59(59)$ & \\
\hline \multicolumn{6}{|l|}{ Gestational age } \\
\hline Preterm (<37 weeks) & $40(61.5)$ & $9(64.2)$ & $13(61.9)$ & $62(62.0)$ & \\
\hline Term (>37 weeks) & $25(38.5)$ & $5(35.8)$ & $8(38.1)$ & $38(38.0)$ & \\
\hline \multicolumn{6}{|l|}{ Birth weight } \\
\hline $\mathrm{BW}(<2.5 \mathrm{~kg})$ & $38(58.4)$ & $9(64.2)$ & $15(71.4)$ & $62(62.0)$ & \\
\hline BW (>2.5 kg) & $27(41.5)$ & $5(35.7)$ & $6(28.6)$ & $38(38.0)$ & \\
\hline \multicolumn{6}{|l|}{ Mode of delivery } \\
\hline LSCS & $28(43)$ & $5(35.7)$ & $7(33.3)$ & $40(40.0)$ & \\
\hline NVD & $37(57)$ & $9(64.3)$ & $14(66.7)$ & $60(60.0)$ & \\
\hline \multicolumn{6}{|l|}{ Risk factors distribution } \\
\hline Prematurity (<37 weeks) & $40(62.0)$ & $6(42.8)$ & $13(61.9)$ & 59 & 0.0009 \\
\hline Maternal fever & $19(30.4)$ & $8(57.1)$ & $14(66.7)$ & 41 & 0.002 \\
\hline Prolonged rupture of membrane $(>18 \mathrm{~h})$ & $23(35.4)$ & $5(35.7)$ & $9(42.8)$ & 37 & 0.03 \\
\hline Preterm premature rupture of membrane & $20(31.6)$ & $4(28.5)$ & $7(33.3)$ & 31 & 0.04 \\
\hline 3 or more vaginal examination after rupture of membrane & $20(30.4)$ & $4(28.5)$ & $6(28.5)$ & 30 & 0.34 \\
\hline Meconium stained liquor & $18(27.8)$ & $1(7.1)$ & $3(14.3)$ & 22 & 0.20 \\
\hline Birth asphyxia (apgar score of $<4$ in $1 \mathrm{~min}$ ) & $12(19.0)$ & $4(28.5)$ & $2(9.5)$ & 18 & 0.30 \\
\hline Prolong labour (>24 h) & $13(19.0)$ & $3(21.4)$ & $1(4.7)$ & 17 & 0.55 \\
\hline Foul smelling liquor & $0(0.0)$ & $1(7.1)$ & $8(38.1)$ & 9 & 0.001 \\
\hline Chorioamniotis & $0(0.0)$ & $1(7.1)$ & $8(38.1)$ & 9 & 0.001 \\
\hline
\end{tabular}


Hence they have limited use in financially constrained setup. Therefore, there is always a need for an infallible cost-effective test for early detection of EONS that could be easily performed. In this study, we have evaluated the effectiveness and importance of the HSS of Rodwell et al., ${ }^{3}$ using UCB in the detection of the EONS and its comparison with PVB.

Males predominantly develop sepsis in our study (Table 1), which is consistent with other studies by Makkar et al., Pramana et al., Dutta et al. ${ }^{4,6,7}$ Preterm neonates predominantly develop sepsis in our study (Table 1), which is consistent with other studies by Makkar et al., Pramana et al.,

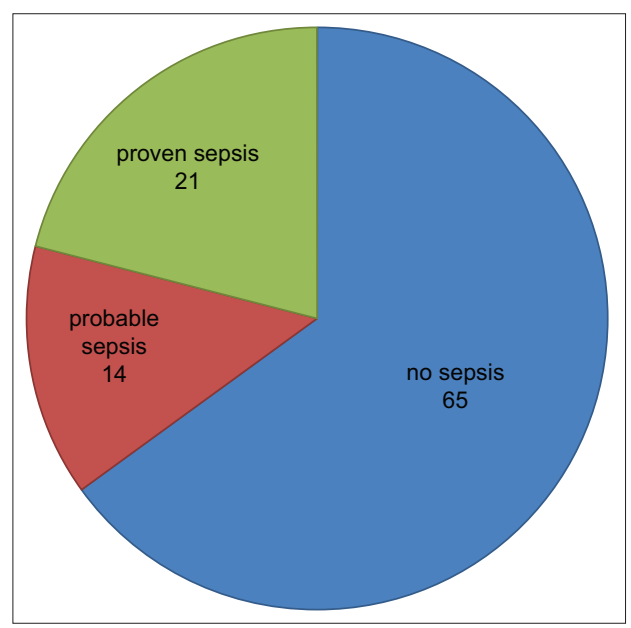

Figure 1: Diagnostic distribution for EONS. No sepsis - 65, Probable sepsis - 14, Proven sepsis - 21. EONS: Early onset neonatal sepsis

\begin{tabular}{cccc} 
Table 3: HSS score in UCB and PVB \\
\hline & \multicolumn{3}{c}{ Final diagnosis } \\
\cline { 2 - 4 } & $\begin{array}{c}\text { Sepsis (Proven+ } \\
\text { Probable) } \\
(\mathbf{n = 3 5 )}\end{array}$ & $\begin{array}{c}\text { No sepsis } \\
(\mathbf{n}=65)\end{array}$ & $\begin{array}{c}\text { Total } \\
(\mathbf{n}=\mathbf{1 0 0})\end{array}$ \\
\hline $\begin{array}{c}\text { HSS in UCB } \\
\text { Positive } \\
\text { (score>3) }\end{array}$ & 26 & 5 & 31 \\
$\begin{array}{c}\text { Negative } \\
\text { (score<2) }\end{array}$ & 9 & 60 & 69 \\
$\begin{array}{c}\text { HSS in PVB } \\
\text { Positive } \\
\text { (score>3) }\end{array}$ & 22 & 7 & 29 \\
$\begin{array}{l}\text { Negative } \\
\text { (score<2) }\end{array}$ & 13 & 58 & 71 \\
Total & 35 & 65 & 100 \\
\hline
\end{tabular}

HSS: Hematological scoring system, UCB: Umbilical cord blood, PVB: Peripheral venous blood
Dutta et al. ${ }^{4,6,7} \mathrm{LBW}$ neonates predominantly develop sepsis in our study (Table 1), which is consistent with other studies by Makkar et al., Pramana et al., Dutta et al., ${ }^{4,6,7}$ There was no significant correlation of sepsis status with NVD and LSCS delivered neonates (Table 1), it is consistent with other studies by Makkar et al., Pramana et al., ${ }^{4,6}$

Risk factors distribution (Table 1) among 100 neonates, the following risk factors shown a statistically significant correlation with EONS with $\mathrm{P}<0.05$, maternal fever, prematurity, prolonged rupture of membrane, premature rupture of membrane, foul smelling liquor, chorioamniotis. Similar findings were reported in other studies by Pramana et al., Dutta et al., Mandot and Gandhi. ${ }^{6-8}$

Out of 35 sepsis (proven+probable sepsis) cases which presented with clinical features of EONS, the $\mathrm{m} / \mathrm{c}$ clinical manifestation was respiratory distress (Table 2). Majority of neonates has shown more than 2-3 clinical features. Similar findings were present in other studies done by Pramana et al., Dutta et al. ${ }^{6,7}$

Statistical parameters of HSS in UCB for detecting EONS are - Sensitivity-74.28\%, Specificity- $92.30 \%$, PPV-83.87\%, NPV-86.95\%. Similar parameters of HSS in PVB for detecting EONS are - Sensitivity-62.85\%, Specificity-87.69\%, PPV-75.86\%, NPV-81.69\% (Table 4). HSS score in UCB in our study has higher sensitivity as compared to PVB and comparable specificity, which can be attributed to more blood sample availability as UCB can be collected easily, effortlessly and is easily accessible without causing any pain to neonate. It is well-known that withdrawing large amounts of blood from a neonate can be challenging and may also lead to iatrogenic anaemia.' For neonates, blood sampling by venipuncture can be difficult, as in routine clinical practice a large proportion of CBC reports were spurious because of the submission of an inadequate volume of blood ${ }^{10}$ and repeated needle prick for adequate blood sample can cause more pain to the neonate. UCB sample is collected before instillation of antibiotics which also adds to its higher sensitivity and it prevents iatrogenic anemia and the introduction of infection. Hence, HSS score in UCB can be used as a screening tool for the detection of EONS.

HSS can be used as a screening test for early diagnosing of EONS and to differentiate infected neonates from the non-infected ones. HSS score in UCB in our study has

\section{Table 4: Comparison of statistical parameters of HSS in UCB and PVB}

\begin{tabular}{lcccc} 
& Sensitivity & Specificity & PPV & NPV \\
\hline HSS in umbilical cord blood & $74.28 \%$ & $92.30 \%$ & $83.87 \%$ & $86.95 \%$ \\
HSS in peripheral vein blood & $62.85 \%$ & $87.69 \%$ & $75.86 \%$ & $81.69 \%$ \\
\hline HSS: Haematological scoring system, UCB: Umbilical cord blood, PVB: Peripheral venous blood, PPV: Positive predictive value, NPV: Negative predictive value
\end{tabular}


higher sensitivity as compared to PVB and comparable specificity, with the certainty of sepsis increasing along with the increasing score.

\section{Limitations of the study}

The present study has some limitations. The sample size was small and the simplification and standardization of the interpretation of this global test (HSS scoring) is still required.

\section{CONCLUSION}

HSS score in UCB can be used as a simple, quick, costeffective, and readily available tool with decent sensitivity and high specificity and can be used as a screening test for detection of EONS. Hence, it can help in the early initiation of treatment for EONS and avoid its devastating outcome. It also helps in avoiding unnecessary instillation of antibiotics and preventing the development of antibiotic resistance.

\section{ACKNOWLEDGMENT}

I thank Dr. Manish Purohit, Associate Professor, Department of Microbiology, M.G.M. Medical College and M.Y. Hospital, Indore, for his support and assistance throughout our study.

\section{REFERENCES}

1. Deorari A. Investigators of national neonatal perinatal database (NNPD) Changing pattern of bacteriologic profile in neonatal sepsis among intramural babies. J Neonatol. 2006;20:1. https://doi.org/10.1177/0973217920060103

2. Eichenwald E, Hansen A, Martin C, Stark A. Cloherty and Stark's Manual of Neonatal Care. $8^{\text {th }}$ ed. Netherlands: Wolters Kluwer Publisher; 2017. p. 598-627.

3. Rodwell RL, Leslie AL and Tudehope DI. Early diagnosis of neonatal sepsis using a hematologic scoring system. J Pediatr. 1988;112(5):761-767.

https://doi.org/10.1016/S0022-3476(88)80699-1

4. Makkar M, Gupta C, Pathak R, Garg S and Mahajan NC. Performance evaluation of hematologic scoring system in early diagnosis of neonatal sepsis. J Clin Neonatol. 2013;2(1):25-29. https://doi.org/10.4103/2249-4847.109243

5. Narasimha A and Kumar ML. Significance of hematological scoring system (HSS) in early diagnosis of neonatal sepsis. Indian J Hematol Blood Transfus. 2011;27(1):14-17. https://doi.org/10.1007/s12288-010-0050-2

6. Pramana K, Kardana I and Nilawati G. Diagnosis accuracy of hematological scoring system in early identification of neonatal sepsis. Bali Med J. 2016;5(3):139-143. https://doi.org/10.15562/bmj.v5i3.310

7. Dutta NR, Medhi $P$ and Hazarika R. Haematological scoring system (HSS) in early diagnosis of neonatal sepsis: A study from tertiary care hospital from north east India. J Evol Med Dent Sci. 2016;5(52):3359-3366.

https://doi.org/10.14260/jemds/2016/777

8. Mandot S and Gandhi JS. Umbilical cord blood culture versus peripheral venous blood culture in early onset neonatal sepsis. Int J Contemp Pediatr. 2017;4(1):53-56. https://doi.org/10.18203/2349-3291.ijcp20164302

9. Schelonka RL, Chai MK, Yoder BA, Hensley D, Brockett RM and Ascher DP. Volume of blood required to detect common neonatal pathogens. J Pediatr. 1996;8(129):275-278. https://doi.org/10.1016/S0022-3476(96)70254-8

10. Connell TG, Rele M, Cowley D, Buttery JP and Curtis N. How reliable is a negative blood culture result? Volume of blood submitted for culture in routine practice in a children's hospital. Pediatrics. 2007;119(5):891-896.

https://doi.org/10.1542/peds.2006-0440

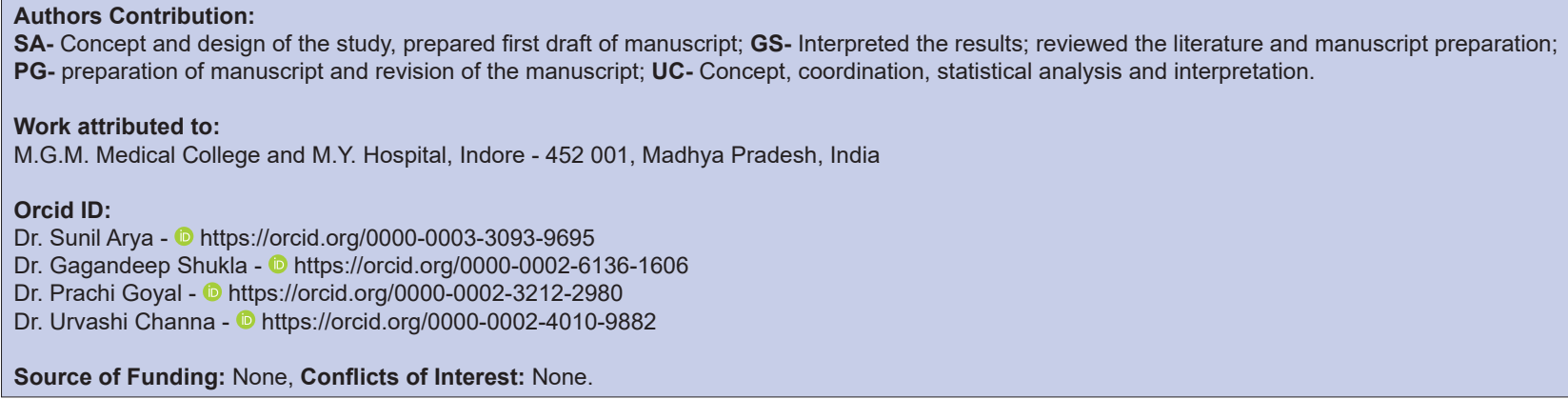

